


Digitized by the Internet Archive in 2007 with funding from Microsoft Corporation 

FOOD FOR THE INVALID AND THE CONVALESCENT 


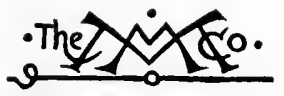

THE MACMILLAN COMPANY

NEW YORK - BOSTON - CHICAGO

DALLAS - SAN FRANCISCO

MACMILLAN \& CO., LIMITED

LONDON - BOMBAY - CALCUTTA MELBOURNE

THE MACMILLAN CO. OF CANADA, Lto. TORONTO 


\title{
FOOD FOR THE INVALID
}

\section{AND}

\section{THE CONVALESCENT}

\begin{abstract}
BY
WINIFRED STUART GIBBS

DIETITIAN FOR THE NEW YORK ASSOCIATION FOR IMPROVING THE CONDITION OF THE POOR;

TEACHER OF ECONOMIC COOKERY, TEACHERS COLLEGE, COLUMBIA UNIVERSITY AUTHOR OF "LESSONS IN THE PROPER FEEDING OF THE FAMILY"
\end{abstract}

New 19 ark

\section{THE MACMULLAN COMPANY}

\section{2}

All rights reserved

27661 
COPYRIGHT, 1912,

BY THE MACMILLAN COMPANY.

Set up and electrotyped. Published March, rgiz.

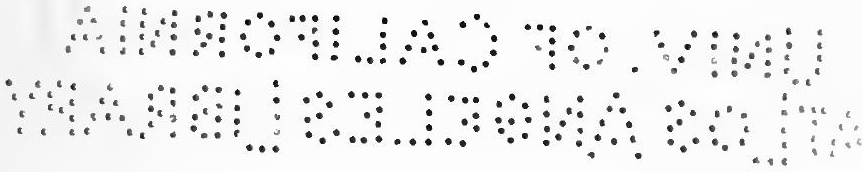

Norboond 扔ress

J. s. Cushing Co. - Berwick \& Smith Co.

Norwood, Mass., U.S.A. 


\section{PREFACE}

Grateful acknowledgments are due to Dr. Theodore C. Janeway, Dr. H. O. Mosenthal, Dr. L. R. Williams, and Dr. Edwards A. Park, for helpful advice in preparing this little book. The work was undertaken at the request of the above physicians, and to its preparation were brought the results of five years' experience as Dietitian for the New York Association for Improving the Condition of the Poor. During this time the working basis has been actual incomes of actual families in relation to the current prices of foodstuffs.

The writer has found that much can be accomplished in the way of prevention of disease by instruction in the very simplest laws of right feeding and good cooking.

The dietaries are reproduced from a former pamphlet, "Lessons in the Proper Feeding of the Family." 
I wish to acknowledge my indebtedness to Miss Fannie M. Farmer, from whose writings I adapt many points for use in this work. 


\section{CONTENTS}

PAGES

General Directions • • • • • • 3-7

How to Buy . . • . . . . 3-5

Preservation of Food that Spoils . . 3

How to Keep Food from Spoiling . . 4

Some Helps toward Keeping Food from Spoiling . . . • • • 4

Why Dirty Stores are Dangerous . . 4

How to Eat . . . . . . 5-6

Kinds of Food to Eat . . . . 5

Necessity for Good Cooking . . . $\quad 5$

Results of Bad Cooking • • . . 6

How to Cook . . . . . . . 6-7

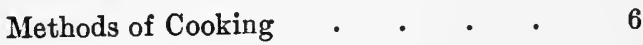

Part I: The Preparation of Each Class of

Foods . . . . . . . 11-48

Drinks . . . . . . . . 11-13

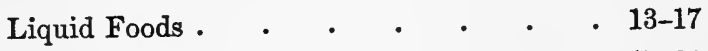

Soups . . . • • • • $17-21$

Meats . . . . . . • . 21-26

Fats . . . . . . . . 26-27

Fish . . . • . • • . $27-29$

Eggs • • • • • • • . 29-30 


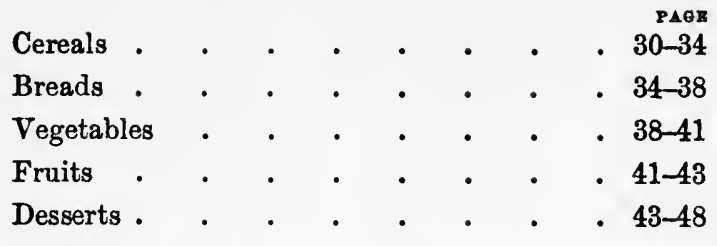

Part II: Special Menus and Diets . . 51-81

Feeding the Healthy . . . . . 51-72

Diet for Children . . . . . . 72-74

Feeding the Sick . . . . . . 75-81 


\section{INTRODUCTION}

Every dispensary physician who is truly interested in the care of his patients realizes how important a contributing factor in much of the ill-health that he sees is the unintelligently chosen and badly prepared food of the patients, and what a beneficial factor simple and properly cooked meals might be in the treatment of many disorders. The social worker sees in addition the economic waste which lack of knowledge and dietetic prejudice bring into just those families of the American community that can least afford any waste. This little book, prepared by Miss Winifred Stuart Gibbs, with the coöperation of Dr. Edwards A. Park and Dr. Herman O. Mosenthal of the Department of Medicine of the Vanderbilt Clinic, aims to help both physicians and social workers in their efforts to treat disease and to conserve health. It has 
been compiled especially with a view toward helping us, the physicians of the Vanderbilt Clinic, in carrying on intelligent dietetic treatment; and it will, I trust, prove of service to dispensary workers generally. By means of the book, Miss Gibbs has added another strong link to the chain that is binding physicians and social workers in a coöperation which is rapidly transforming for the better the spirit and methods of American dispensaries.

\section{THEODORE C. JANEWAY, M.D.}

Vanderbilt Clinic, College of Physicians and Surgeons, Columbia University. 


\section{GENERAL DIRECTIONS}





\section{F00D FOR THE INVALID AND THE CONVALESCENT}

\section{GENERAL DIRECTIONS$$
27661
$$ \\ HOW TO BUY}

IT is not necessary to buy the most expensive food in order to get the best; the important thing is to get the right food, so that the money spent will give as much strength as possible.

Always buy a fixed quantity of any food, instead of "five cents' worth " or " ten cents' worth" ; in this way every penny will bring in a penny's worth of food. In other words, ask for "a half pound" or "a quarter pound," "a quart," "a peck," or a "bushel."

Preservation of Food that Spolls

Food is preserved in several ways -

1. By sugar. Example: Fruit preserves.

2. By drying. Example: Dried apples.

3. By salt. Example: Salt fish.

4. By chemicals - a commercial practice.

5. By freezing. Example: Cold storage of meat. 
How to keep Food From Spolling

The "spoiling" of food is caused by the presence of quantities of small living things. These grow on many varieties of food and cause what we call "decay."

Some Helps toward keeping Food From SPOILING

1. Have everything - room, walls, floor, tables, and dishes - absolutely clean.

2. Keep hands and clothing clean.

3. Wherever practicable boil dishes for ten minutes after they have been used for anything that is not quite fresh.

4. Keep insects away.

5. Keep room sunned and aired.

6 . Never buy stale meat, fruits, vegetables, eggs, or milk.

7. Never put clean food near food that is spoiled.

Why Dirty Stores are Dangerous

Dirty stores have many corners where these small living things can grow and increase. Dust gives them a good nest, flies 
may carry them about, foul odors may be absorbed by food. Food that has begun to spoil may cause other food to spoil, simply by touching it. Dirty stores may make the salespeople ill, and these persons may cause food to spoil, simply by handling it.

\section{HOW TO EAT}

Kinds of Food to EAT

1. Food that gives muscular strength.

2. Food that gives heat.

3. Food that keeps the blood in good order.

4. Food that gives working power.

5. A mixed diet of meat and vegetable food is the best in order to get these results.

6. Vegetables and fruit, while they do not contain much nourishment, are necessary to prevent some diseases. Grown people, and still more children, who never eat them, often develop scurvy.

\section{Necessity for Good Cooking}

Unless food is well digested it will not give strength, and it will not be well digested 
unless it is well cooked. Bad cooking may destroy the health of the entire family, and so lessen the earning power and general prosperity.

\section{Results of Bad Cooking}

Badly cooked meat will be tough, dry, and indigestible.

Badly cooked cereals will be pasty and sticky.

Badly made bread will be heavy.

Badly made puddings will be heavy and sticky.

Badly cooked vegetables will have a hard, woody substance in them.

\section{HOW TO COOK}

Food is cooked to make it palatable, to render it digestible, and to destroy all dangerous bacteria.

\section{Methods of Cooking}

1. Boiling: Cooking in boiling water.

2. Stewing: Cooking in simmering water.

3. Steaming: Cooking over boiling water.

4. Broiling: Cooking over direct heat. 
5. Roasting - Baking: Cooking in heated oven.

6. Braising: Combined steaming and baking.

7. Frying: Cooking in deep fat. (Should not be used for sick persons.)

8. Sautéing: Cooking in a very little fat. (Very indigestible.)

9. Fricasseeing: Sautéing and serving with a sauce. Tough meat is boiled before fricasseeing. This is not good for sick persons. 



\section{PART I}

\section{THE PREPARATION OF FOOD}





\section{THE PREPARATION OF EACH CLASS OF FOOD}

\section{DRINKS}

Drinks in Place of Tea and Coffee Milk. - A real food. Makes blood and strength.

"Cambrie Tea." - Equal parts of hot milk and water sweetened to taste.

Cocoa. - A food drink.

Cereal Coffee.-A drink for variety. Will not affect the nerves.

Cocoa Shells. - The outside of the cocoa bean broken in small pieces; not a food, but an excellent drink.

\section{RULES FOR MAKING Hot DRINKS}

Coffee. - 1 heaping tablespoon of coffee for each cup. Measure amount of water needed, add half of this cold to coffee, stirring it thoroughly; let other half of water boil and add to coffee as soon as the cold water has come to a boil; boil three minutes, 
let stand ten minutes, pour one tablespoon of cold water down spout to settle coffee. Always scald coffeepot after using.

Tea. - Scald teapot, put in it 1 teaspoon tea for each cup required, pour required number of cupfuls of boiling water on tea, let stand three minutes, and serve. Never boil the tea.

Cocoa Shells. -1 cup shells, 3 pints water; boil slowly two hours. Strain and serve with milk and sugar. The strength of the drink may be changed to suit the taste.

Cocoa (1 cup). - 1 tablespoon cocoa mixed with half tablespoon sugar. Stir in enough boiling water to make a paste, add half cup boiling water, boil 15 minutes, add half cup milk and serve.

Cereal Coffee.-Follow directions on package if the coffee is to be strong. Many find that half the quantity spoken of on the package will make a satisfactory drink.

\section{RUles for making Cold Drinks}

Lemonade. -2 tablespoons of syrup, 3 tablespoons lemon juice, 1 cup cold water. 
Strain lemon juice and add cold water and syrup.

Orangeade. - May be made the same way. Very refreshing summer desserts may be made from a frozen mixture of water, fruit juice, and sugar.

\section{LIQUID FOODS}

\section{MILK}

\section{Points to remember about Milk}

Be sure you buy clean milk from a clean milkman, and then be careful to keep the milk clean.

Bottled milk is cleaner than loose milk, so buy bottled milk if possible. At least buy bottled milk for the children, especially during hot weather. If there is dirt on the inside of the milk bottle when it is delivered to you, refuse to accept it. Use milk bottles and milk pails for milk and for no other purpose than to hold milk. If loose milk is bought by the quart, wash the pail and scald it before sending the pail to the store. Keep the clean pail upside down when not in use. When send- 
ing for milk, put the cover on the pail. When the pail contains milk, keep the cover on to keep out dust, dirt, flies, and animals.

Buy milk only at clean stores where the milk is kept cold by thorough icing.

Remember that dirty milk causes sickness and death, especially among babies. If you are in doubt as to the cleanliness of your milk, boil it and then keep it cold; but do not continue to give boiled milk to a baby except on a doctor's advice.

Keep milk bottles and milk covered while they contain milk.

Do not stand milk on the back of the stove or on a sunny window sill or in a warm place.

Keep the milk as cold as possible. Keep it on ice if possible.

Wash milk bottles thoroughly before returning them to the milkman.

Never drink milk directly from the bottle or from the pail.

If there has been a contagious disease in the house, wash the bottles carefully with soap and water and then scald the bottles 
thoroughly before returning to the milkman.

Keep the milk clean and cold, and insist upon getting only cold and clean milk.

From bulletin issued by the Committee on Milk Consumers, being a standing committee of the New York Milk Committee.

Often you hear people say, "I cannot afford to buy milk," but this is because they do not understand that milk is a food, and when it is properly used it is not necessary to spend so much for other food.

\section{Milk RECIPES}

Kumyss. -

2 tablespoons lukewarm water

$\frac{1}{4}$ yeast cake

4 cups milk

$1 \frac{1}{2}$ tablespoons sugar

Heat milk until lukewarm, add sugar and yeast which have been dissolved in the warm water. Fill scalded bottles to within two inches of top, cork, and shake. Lay bottles on side over night in warm room, then put on ice for twenty-four hours. Shake the bottles occasionally. 
Junket. - This is a preparation of milk that is easily made and is very nourishing and easy to digest.

1 qt. lukewarm milk
3 tablespoons sugar
1 tablet
1 teaspoon cold water
Any flavoring

Dissolve tablet in water. Warm milk in following manner. Pour into an agate pan, and if ice cold, stand pan in boiling water five minutes, if merely cooled by ice, three minutes. Flavor, sweeten, add dissolved tablet, pour into cups, stand in warm room, do not shake for a half hour.

Cheese. - Every housekeeper should learn how to use cheese properly, as it has much nourishment in small space. Eaten in large quantities, it will upset the stomach; but a reasonable quantity, grated or chopped fine, can be used in many ways and will add greatly to the strength-giving quality of the food.

Cheese Fondu. -

1 cup milk

1 cup bread crumbs

$\frac{8}{4}$ cup grated cheese

1 egg

Salt, pepper and mustard 
Soak bread crumbs in milk, heat, add cheese, season, and when cheese is melted and stirred through crumbs, add beaten egg and remove from fire. Spread on crackers or toast.

Hominy baked with Cheese.-Prepare boiled hominy in the ordinary way; stir grated cheese $\left(\frac{1}{4} \mathrm{lb}\right.$. to 2 cups of cooked mush) through while hot, make into mound, dot with butter, and brown in oven. Any cereal can be used instead of hominy.

Another Method. - Grated cheese can be stirred into any thin porridge or gruel, to suit taste, and will add much to such a diet.

SOUPS

The Making of Soups

Classes of Soups.-

1. Soup made with "stock."

2. Soup made without "stock."

MATERIAl From Which StOck MaY BE MADE

Beef Mutton Poultry Fish 


\section{RULES FOR MAKING STOCK}

1. Place material in cold water.

2. Add salt.

3. Bring slowly to boiling point.

4. Simmer gently until "strength" is drawn out.

5. Add flavoring during last hour of cooking.

6. Cool.

7. Skim off fat.

Stock is used as foundation for soup, and vegetables, rice, etc., are added to suit the case. Often the doctor orders a plain, clear stock seasoned with salt and pepper.

\section{Beef Stock}

$2 \mathrm{lb}$. beef with bone

1 qt. cold water

$\frac{1}{2}$ teaspoon salt

Carrot

Potato

Tomato 1 tablespoon of each

Celery

Wipe meat and bone with cloth wrung out of cold water, cut meat in small pieces, cover with cold water, soak twenty minutes and 
bring slowly to boiling heat, then simmer slowly for five hours. Add vegetables and cook an hour longer, strain, and cool. During the cooling, if a clear stock is desired, skim off the "scum" that rises to the top.

\section{Beef Juice. - A light food.}

Broil a piece of round very lightly, cut in pieces, and press in lemon squeezer until all juice is taken out; add salt. Use as doctor directs.

\section{Beef Tea.-A stimulant.}

Cut thick round steak in bits, place in glass fruit jar, sprinkle with salt, screw on cover, place jar of meat in saucepan of cold water; bring slowly to boiling point, simmer until meat is colorless and broth rich and strong.

$$
\begin{aligned}
& \text { Mutton Broth.- } \\
& \qquad \begin{array}{l}
2 \text { lb. lamb or mutton } \\
5 \text { cups cold water } \\
\frac{3}{4} \text { teaspoon salt }
\end{array}
\end{aligned}
$$

Make the same as beef stock; add $1 \frac{1}{2}$ tablespoons well-cooked rice after broth is skimmed and reheated. 
Chicken Broth.-

$3 \mathrm{lb}$. chicken

3 pt. cold water

1 teaspoon salt

2 tablespoons rice

After chicken is cleaned, wipe with cloth and cut in pieces at joints. Make broth same as beef and mutton broth.

Soups without Stock. - These are made of cooked and strained vegetables with milk or stock added. Soups of this kind need to be thickened slightly or "bound" with a few spoons of flour blended smoothly with some liquid; otherwise the vegetable part would separate and the soup would not be smooth.

Cream Soups. - These are made with "white sauce" or thickened milk and strained vegetable pulp.

Cream of Pea.-

$\frac{1}{2}$ cup canned or green peas

$\frac{1}{2}$ cup cold water

$\frac{1}{4}$ teaspoon sugar

1 cup hot milk

$\frac{1}{2}$ tablespoon butterine

$\frac{1}{2}$ tablespoon flour

Salt

Pepper 
Drain peas, add sugar and cold water, and cook ten minutes. Rub through a strainer. Melt butter, rub in flour, pour in scalding milk, boil ten minutes, season and add to pea pulp. Cook five minutes.

Other cream soups are made in the same way, changing the thickness to suit case.

\section{MEATS}

\section{How to BUY MeAT}

Many of the cheaper cuts of meat will give a large amount of strength, and may be made tender by long, slow cooking. Do not send for "fifteen cents' worth of steak," but learn the cuts and prices, so that the family may receive every ounce of food paid for. Learn to read a scale, watch meat while it is being weighed, and, if possible, have a good scale at home to test correctness of the butcher's.

Always insist on all bones and trimmings being sent with the meat and use them in soup.

Ask for a piece of suet, even if it is not to be used at the time. Try it out, strain it, 
and put it away in a clean cup. Save all trimmings of fat to be tried out in the same way, as this dripping is wholesome food for well people. When a sick person cannot digest fat, the trimmings from his meat before it is cooked will furnish valuable food for the well members of the family.

Here is a list of the cuts of beef and mutton in common use, with average price per pound in New York City.

\section{BEEF}

CuT

Shin

Neck

Chuck

"Short chuck"

Flank

Skirt steak

Rump

Round
Prick

$\$ .08-.12$

$.12-.14$

.14

$.12 \frac{1}{2}$

$.12-.14$

$.09-.12$

$.14-.18$

$.18-.22$
UsE

Soup

Stew

Braising or pot roast

Stew

Baking

Braising

Corned beef

Broiling, pan broiling, beef juice, beef tea

\section{Motton}

$\begin{array}{ll}\text { Shoulder lamb } & .12 \frac{1}{2} \\ \text { Breast of lamb } & .10 \\ \text { Leg mutton } & .14 \\ \text { Shoulder chops } & .14\end{array}$

Stew - broth

Stew or baked

Boil or roast

Broiling or pan broiling, braising 
The following cuts are expensive and need be used only when digestion is weak from illness.

$\begin{array}{lrl}\text { Leg of lamb } & \$ .16-.18 & \text { Roast } \\ \text { Rib chops } & .22-.25 & \text { Broiling or pan broiling } \\ \text { Prime ribs of beef } & .20-.22 & \text { Roast } \\ \text { Sirloin steak } & .20-.22 & \text { Broiling }\end{array}$

The Cooking of Meat

Meat used for Sick People

\begin{tabular}{llll}
\multicolumn{1}{c}{ Befr } & Mutroy & Pork & Poultry \\
Round & Rib & Bacon & Chicken \\
Prime rib & Loin & & Fowl \\
& & & Turkey
\end{tabular}

Ways of cooking Meat for Sick People

Broiling or pan broiling.

Roasting.

\section{DesCrIPTION OF COOKING}

Broiling. - Tender steak or chops are best broiled. Place in a wire broiler, hold over a clear fire until it turns a whitish brown, then turn and do the same thing to the other side. This sears the meat and keeps in the juice. After searing both sides, turn meat back and forth, but less often, until both sides are nicely browned. Sprinkle with salt, place on hot plate, add a bit of butter, and serve at once. 


\section{Cooking in Buttered Paper}

A chop can be broiled in a paper case, and this will be a way to retain all the juices of the meat.

Method. - Butter a half sheet of foolscap or stiff white paper, lay chop in middle, fold edges on side and ends, so that there will be a half inch fold all around. Begin near outer edge, so that fold can be made three times. Broil in wire broiler for ten minutes, being careful not to set fire to paper.

\section{Pan Broiling}

If one has no broiler, or cannot have use of a good broiling fire, pan broiling is almost as good, and the meat very nearly as digestible.

First, have a hot frying pan just oiled with a bit of fat held on a fork. Rub this over the pan, but do not leave any loose grease. When pan is sizzling hot, put in the meat, pressing it down first on one side and then on the other. This seals up the cut ends of the muscles just as is done by holding meat over the fire, and is called "searing." When both sides are well seared 
and no red color remains, turn on pan until brown, and treat exactly the same as broiled meat.

\section{To Roast Meat}

Sear roast on hot baking pan, rub with salt, cover with another deep pan, cook according to size - allow 15 minutes for each pound. After the cooking is well begun, the meat must be "basted" every 20 minutes. This is done by taking up juice in pan with a large spoon and pouring it over meat. If necessary a little hot water may be added to pan. During last hour of cooking remove cover so that meat will brown.

Gravy.-The only kind of gravy that is good for sick people is the clear juice of the meat. "Made" gravy, with flour and fat added, is hard to digest.

\section{Meats forbidden Sick Persons}

All fried meats.

"Warmed over" meat, such as stews and hash. Pork.

Scraped Beef. - This is the form most easily digested. 
Use a dull knife or spoon, scrape the soft part free from the sinewy and stringy parts; serve the soft part raw, between slices of bread and butter, or make into small cakes and broil.

\section{Meat Jelly}

1 cup beef stock

$\frac{3}{4}$ teaspoon pulverized gelatine

Stir gelatine into stock while it is at boiling heat. Season with salt and celery salt, if liked. Pour into small cups which have been dipped in cold water.

\section{FATS}

It is very important that we have plenty of fat in our food. Butter is one of the most wholesome forms of fat, but it is expensive, and it is worth while to learn about oleomargarine or "butterine." This is made of pure, sweet fats, and has some butter mixed with it, in the best quality, so that it tastes very good. Butterine costs much less than butter, is good food, and is much better than poor butter. 
Salad oil is another good fat to use, and the fat of beef is good, but children sometimes object to eating it. In such cases, give some other kind of fat.

\section{FISH}

\section{How тo BuY}

Serve fish once or twice a week instead of meat.

Below is a list of moderate priced fish in New York City.

The "Market Cod" is only for boiling.

"Market Cod"

$\$ .10-.12$

Haddock

.07

Weakfish

$.08-.10$

Flounder

$.08-.10$

Porgies

$.06-.10$

The Cooking of Fish

Best Ways of Cooking

Boiling. Broiling. Baking.

\section{Boiled Fish}

Add a few drops of lemon juice or vinegar and sprinkle a little salt in the boiling water in which fish is to be cooked. Fish like 
haddock may be boiled whole; if too large for this, cut thick slices, tie in cheesecloth, and cook until flesh leaves the bonestwenty to thirty minutes, according to size.

\section{Broiled Fish}

Clean fish, split down the back, lay on greased wire broiler, and turn over quickly; heat until thoroughly cooked.

\section{Baked Fish}

Clean fish, make cut in side, fill with nicely seasoned stuffing, and bake in moderate oven.

\section{Oysters and Clams}

Raw oysters may be given if doctor allows. Clams should be used only in broth.

\section{Oyster Soup}

1 pt. oysters 2 cups milk

2 tablespoons butter

Rinse oysters in cold water. Heat liquor to boiling point, strain, add oysters, cook until edges curl, add to hot milk, add butter, season, and serve. 


\section{Clam Broth}

Scrub clams, place in kettle with cold water, steam until shells open, strain liquor, cool, clean, and reheat to serve.

\section{EGGS}

\section{How to BuY}

Before buying eggs, test them by shaking. Stale eggs will rattle in the shell; fresh eggs will remain solid and will not shake.

\section{The Cooking of Eggs}

\section{Boiled Eggs}

Plunge eggs in boiling water, cover, place on back of stove, and allow to remain for five or ten minutes, according to degree of hardness desired. If the water is allowed to boil after eggs are in, the white will be tough and indigestible.

\section{Scrambled Eggs}

Break eggs into a bowl, add one tablespoon of milk for each egg, beat with fork, pour into greased frying pan, add salt and 
pepper, and cook until creamy, stirring constantly. Be very careful not to cook eggs until they are hard.

\section{Creamy Egg}

For each beaten egg use a third of a cup of milk, season with salt, and place in inner part of double boiler. Cook over steam of simmering, not boiling, water until the mixture is creamy. Remove cover occasionally and stir the mixture as it thickens from the sides and bottom of the boiler.

\section{Dropped Egg}

Break an egg into a saucer, slip carefully into a saucepan of hot (not boiling) water; cook until white is like jelly. Serve on toast.

\section{CEREALS}

\section{How to Bur}

Buy uncooked cereals rather than the cooked cereals in packages, if you wish to get your money's worth. Buy at a clean store; and if loose cereal is bought, see that 
it has been kept in a dry place. Watch cereals for any little live things that may get in, especially in warm weather.

\section{The Cooking of Cereals}

\section{Points to Remember}

1. Have water boiling.

2. Add salt.

3. Stir cereal in slowly, cook until thickening begins.

4. Place in double boiler and cook several hours, according to kind. It may be cooked over night.

5. Different kinds of cereals need different amounts of water. A general rule is two and a half times as much water as grain, and a teaspoon of salt for every quart of water.

\section{Different Kinds of Uncooked Cereals}

Fine or ground cereals all need long cooking, and most of them need several more cups of water for each cup of cereal than do the flaked varieties. 


\section{Table of Fine Cereals}

KTND

Corn meal

Hominy

Farina (gruel)

Irish Oatmeal

Scotch Oatmeal
QUantity

1 cup

1 cup

2 tablespoons

1 cup

1 cup
WATER

6 cups 3 hr.

4 cups 2 hr.

2 cups $1 \mathrm{hr}$.

6 cups 3 hr.

6 cups 3 hr.

\section{Table of Coarse Cereals}

KIND

Rolled oats

Rolled wheat

Rice
Quantity

1 cup

1 cup

1 cup
WATER

$2 \frac{1}{4}$ cups

$2 \frac{1}{4}$ cups

6 cups
TIME

2 hr.

$2 \mathrm{hr}$

$1 \mathrm{hr}$.

The Cooking of Gruels

Oatmeal Gruel

$\frac{1}{2}$ cup rolled oats

$\frac{1}{2}$ teaspoon salt

3 cups boiling water

Add salt to boiling water, stir in oats, boil directly over fire for five minutes, then place saucepan in a larger one containing boiling water, according to direction given for making porridge or mush, and cook for an hour. Strain gruel, heat to boiling, and if the doctor allows milk, add milk to suit taste. 


\section{Barley Gruel}

Two ounces pearl barley; soak over night in cold water; add 1 qt. of water; let boil until reduced to a pint.

\section{Barley Gruel from Prepared Barley}

Follow exactly directions on package, according to thickness desired.

\section{Rice Water \\ 2 tablespoons rice \\ 3 cups cold water \\ Salt to season}

Wash rice; heat gradually to boiling point, and let boil two hours. Strain, reheat, and add salt. If too thick, add a little boiling water.

\section{Cracker Gruel}

1 tablespoon sifted cracker dust

1 cup milk

$\frac{1}{8}$ teaspoon salt

Scald milk, add cracker dust, cook over boiling water for five minutes. Season with salt. 


\section{Farina Gruel}

See table, p. 32 .

\section{Indian Meal Gruel}

1 tablespoon corn meal

Cold water to make a paste

$\frac{1}{2}$ tablespoon flour

$\frac{1}{8}$ teaspoon salt

1 pint boiling water

Mix dry materials; stir them smooth in cold water, then stir this smooth paste into boiling water and cook in double boiler for one hour.

\section{BREADS}

\section{How to Bur}

Always buy the stale loaves when possible, as there is more nourishment for the money spent than in the fresh bread. If it is impossible to obtain stale loaves, buy enough at one time to last two days provided there is a clean place to keep it. Stale bread is better food than fresh.

\section{When to make Bread at Home}

If the housekeeper is strong-if there is a place to keep bread clean. A large family 
can save at least ten cents a day by using homemade bread, and it may be well to buy a bread mixer, if the housekeeper is not strong. The bread mixer will cost about $\$ 2.50$. Flour is cheaper when bought by the large bag than by the pound.

\section{Kinds OF BREAD}

1. "Unleavened" bread, or bread containing nothing to make it "rise." This kind of bread is baked in thin sheets or wafers.

2. Bread raised with baking powder.

3. Bread raised with yeast.

The latter kind is the most easily digested in all cases. It should never be given fresh. Use yeast bread at least twenty-four hours old. Toast it if the doctor orders it.

\section{Toast}

Toast is properly made by a slow drying and browning of the bread, rather than by a quick browning of the surface, which leaves the inside of the slice soft and sticky. Well-made toast is more nearly ready for digestion than untoasted bread, as the heat begins the work of digestion. 


\section{Bread}

Homemade bread is really cheaper than bakers', even when flour is high-priced, for it gives nearly twice as much real food. During the summer, when a fire is not kept, bread can be baked at almost any bakery for one cent a loaf.

\section{Rule - One Loaf}

1 cup lukewarm water

$\frac{1}{2}$ teaspoon salt

$\frac{1}{2}$ teaspoon sugar

$\frac{1}{2}$ yeast cake

Flour to make soft dough

Dissolve yeast in a little lukewarm water, stir into one cup of lukewarm water, add salt and sugar, then gradually add flour, beating and then kneading to a soft dough. Let rise until it doubles in size, roll out air bubbles, shape into a loaf, cover with melted fat, let rise one hour, then bake.

2 cups rolled oats

\section{Oat Wafers}

2 cups flour

4 tablespoons sugar

$\frac{1}{2}$ teaspoon salt

6 tablespoons shortening, half butterine and half lard, hot water 
Mix first four materials, rub in shortening, add just enough hot water to make dough hold together, roll as thin as possible, cut out and bake until crisp and brown.

\section{Graham Bread}

$\frac{1}{3}$ cake yeast
1 cup scalded milk (cooled)
$\frac{3}{4}$ cup lukewarm water
2 tablespoons lard
1 teaspoon salt
$\frac{1}{4}$ cup molasses
$2 \frac{1}{2}$ cups graham flour
$1 \frac{1}{2}$ cups white flour

Dissolve yeast cake in lukewarm water, add melted lard to milk, add salt, molasses, and yeast, then beat in flour. Cover, set to rise over night. In the morning mix well, turn into greased pans, let rise until double in size, bake one hour.

\section{Rolls}

White or graham rolls may be made from bread dough, and, if desired, a tiny bit of butter may be folded into each roll before putting in pan. Rolls need not stand in pan so long as bread nor do they need so long to bake. 


\section{Corn Bread}

1 cup water

$1 \frac{1}{2}$ cups yellow meal

2 cups white flour

2 tablespoons of dripping

$\frac{1}{2}$ teaspoon salt

5 teaspoons baking powder

2 tablespoons sugar

1 egg

1 cup milk

Mix all dry materials, beat into milk and water, add beaten egg, pour in shallow pans, bake $\frac{3}{4}$ of an hour.

\section{VEGETABLES}

\section{How to Bux}

Any fruit or vegetables which have been on stands or carts must be carefully prepared for use. If boiling is part of this preparation, they are comparatively safe. Skin of fruit must be washed or removed altogether. It is not true economy to buy specked or overripe fruit, as its use endangers health. On the other hand, unripe fruit is also unsafe. 


\section{How to cook Vegetables}

Nearly all vegetables contain a woody substance which must be softened before the vegetable is fit for food. They also contain starch, which if put to cook in cold water becomes like a paste, but if started in boiling water is easily digested. Salt should be added at the start to improve the flavor.

STARCHY AND WOOdY

VEGETABLEg

Green Vegetables

(Cook in boiling water)

Potatoes

Lettuce

Beets

Turnips

Carrots

Squash

Dried peas, beans, and lentils

Dried onions.

Celery

Spinach

Young onions

Green peas

String beans

Corn

Cabbage

\section{Potatoes}

Baked potatoes are the best for persons who have been ill.

\section{Dried Vegetables}

Should be soaked over night, cooked until very tender, then rubbed through a sieve and used according to doctor's orders. 
Use of Vegetables for the Sick

Let the doctor select the vegetables to be given; then follow directions very carefully.

A general rule is that the green vegetables, served crisp, may be allowed occasionally, but more often should be given boiled, strained, and warmed either in a cream soup (see p 20), or as a vegetable with hot milk, slightly thickened.

\section{Spinach}

Wash very thoroughly, place in kettle without water, cover, place on back of stove, heat slowly until juice begins to cook out, then bring to front of stove and cook in its own juice until very tender. Chop fine, season, and serve.

\section{Carrots}

These are very wholesome for well persons. Wash, scrape, cook in boiling salted water, serve mashed or in a cream sauce.

\section{Cabbage}

This is inexpensive and very wholesome served shredded, raw, or boiled with a cream sauce. 
For cream sauce see p. 20.

Almost any vegetable can be served in this sauce, or if made thinner, we have cream of vegetable soup. (See p. 21.)

\section{FRUITS}

\section{How to Bux}

Unripe fruit and overripe or specked fruit are both dangerous.

\section{Fruits that May be UnRIPe}

\section{Bananas Plums Pears Peaches}

Bananas are not fit for food unless skins are beginning to turn dark. If unripe, they are very indigestible; the stringy part should be scraped off.

\section{The Serving and Cooking of Fruit}

\section{Baked Apples}

Wipe apples, remove core, place on flat dish, fill the holes with sugar, cover bottom of dish with boiling water, baste often, bake until very soft. 


\section{Stewed Apples}

Pare and quarter two apples, cook in a syrup made of one half cup of sugar boiled in half cup of water. Cook until tender, but do not allow apples to lose their shape.

\section{Stewed Apple Sauce}

Quarter and pare apples, sprinkle with sugar, cover with water, boil until very soft, and rub through a sieve.

\section{Prune Sauce}

Wash prunes, cover with cold water, and stew until soft; then mash through sieve. Do not use sugar. A little lemon juice may be added for flavoring.

\section{Stewed Dried Fruit}

Wash, soak in cold water, drain, and stew until soft. Add sugar if necessary, but many varieties are good without. Apricots need sugar, as they are very tart.

\section{Oranges}

Serve the juice only, or remove the tough white skin and serve only the juicy soft pulp. 
Stewed Fresh Berries

Sprinkle berries with sugar, add enough water to moisten, stew until soft. Strain if doctor orders. If berries are very juicy, no water need be added.

\section{DESSERTS}

Baked Indian Pudding

1 qt. milk boiling

$\frac{1}{4}$ cup corn meal scalded in the milk

$\frac{1}{2}$ cup sugar

$\frac{1}{2}$ cup molasses

$\frac{1}{8}$ teaspoon salt, a little ginger

Mix in order given and bake three hours.

Rice with Sugar and Cinnamon

Plain boiled rice makes a good dessert, sprinkled with granulated sugar which has been mixed with ground cinnamon to suit the taste.

\section{Rice Pudding without Eggs}

Wash 4 tablespoons rice, stir into 1 qt. milk, add 4 tablespoons sugar, 1 tablespoon butterine, $\frac{1}{2}$ teaspoon salt. Bake until thick and creamy, about three hours. 


\section{Cornstarch Pudding}

1 qt. scalded milk

$\frac{1}{2}$ cup cornstarch

$\frac{1}{4}$ cup sugar

$\frac{1}{4}$ teaspoon salt

1 teaspoon vanilla or a little grated nutmeg

2 eggs

Stir cornstarch in a little cold water, add to boiling milk; add sugar and salt, stir until thick and smooth, cook fifteen minutes over hot water, add flavoring, remove from fire, and add yolks of eggs; then fold in stiffly beaten whites.

\section{Chocolate Pudding}

Melt 3 tablespoons cocoa, add sugar and $\frac{1}{3}$ cup boiling water, stir into boiling pudding (cornstarch) before adding the egg.

\section{Orange Cream}

Yolk of one egg

$\frac{1}{2}$ tablespoon sugar

3 tablespoons orange juice

Speck of salt

White one egg

Beat yolk of egg, add orange juice, sugar, and salt, cook over hot water until it just 
begins to thicken, fold stiffly beaten white all through, until it is puffy.

\section{Tapioca Cream}

$\frac{1}{4}$ cup pearl tapioca

or

$1 \frac{1}{2}$ tablespoons minute tapioca

$1 \mathrm{pt}$. milk

2 eggs

1 teaspoon vanilla

$\frac{1}{4}$ cup sugar

Salt

Soak tapioca in cold water one hour, strain, stir into milk, cook over boiling water until tapioca is very soft and transparent, add sugar and beaten egg yolks, take from fire and fold in stiffly beaten whites, and finally the vanilla. Cool before serving.

\section{Baked Custard}

1 egg

$\frac{2}{3}$ cup scalded milk

$1 \frac{1}{2}$ tablespoons sugar

Few grains salt

Nutmeg to flavor

Beat egg slightly, pour on hot milk slowly, add sugar and flavoring, bake until firm in cups, set in pan of hot water. 


\section{Steamed Custard}

\section{Yolks of 2 eggs \\ 4 tablespoons sugar \\ Few grains of salt \\ 2 cups scalded milk \\ $\frac{1}{4}$ teaspoon vanilla \\ $\frac{1}{2}$ tablespoon cornstarch}

Beat yolks, add sugar and salt, stir constantly while adding hot milk, which has been thickened with cornstarch. Cook in small saucepan set in pan of hot water until mixture thickens and coating forms on a spoon. Strain and cool.

\section{Lemon Water Ice \\ 1 quart of water \\ 2 cups sugar \\ $\frac{3}{4}$ cup of lemon juice}

Make a syrup by boiling water and sugar twenty minutes, add lemon juice, cool, strain.

To Freeze. - Place mixture in a small granite pail, place pail in larger pail, with layer of chopped ice under inside pail, then pack space between pails with coarse salt and chopped ice, three cups of ice for each 
cup of salt. Turn inner pail constantly until mixture begins to freeze, then scrape from sides of pail, continue freezing, scrape again, and so on until thick.

\section{Homemade Ice Cream}

A simple boiled custard may be frozen according to directions for freezing lemon ice, and is nourishing and inexpensive when eggs are cheap.

$$
\begin{aligned}
& \frac{1}{4} \text { cup flour } \\
& 2 \text { teaspoons vanilla } \\
& 2 \text { eggs } \\
& 1 \text { cup sugar } \\
& 1 \text { qt. milk }
\end{aligned}
$$

Scald milk, dissolve sugar in hot milk, thicken with flour which has been rubbed smooth in a little cold milk. Cook over boiling water twenty minutes, add beaten eggs, cook three minutes, add vanilla; cool and freeze.

\section{Gelatine Dishes}

\section{General Remarks}

Gelatine dishes may be varied by choosing different fruit juices for flavoring or 
different wines when the physician orders stimulants. They may also be made attractive by stirring in stiffly beaten white of egg while the gelatine is hot.

\section{Proportions}

To each teaspoon of powdered gelatine, allow two tablespoons of cold water for dissolving and six tablespoons of other liquid; this last includes the boiling water.

\section{Lemon Jelly}

1 teaspoon powdered gelatine dissolved in two tablespoons cold water

4 tablespoons boiling water

2 tablespoons sugar

2 to 3 tablespoons lemon juice

Soak gelatine in cold water, add the boiling water, lemon juice, and sugar. Strain and cool.

\section{Wine Jelly}

1 teaspoon powdered gelatine

1 tablespoon cold water

2 ounces sherry

$1 \frac{1}{2}$ tablespoons lemon juice

2 tablespoons boiling water

Make the same as lemon jelly. 


\section{PART II}

\section{SPECIAL MENUS AND DIETS}





\section{SPECIAL MENUS AND DIETS}

\section{FEEDING THE HEALTHY}

The following bills of fare are meant to show how to plan meals so that the right foods will be put together. The first set does not give sufficient variety to keep the family well, but it is intended to show that it is worth while to give thought and care to even a very small food allowance.

All the bills of fare are planned for a family of man, wife, and three children, from two to twelve years of age.

\section{First Set of Bills of Fare}

\section{Food Supplies for Week}

\begin{tabular}{lc} 
Food & Asroust \\
Milk & $7 \mathrm{qt}$. \\
Eggs & 9 \\
Cheese & $\frac{1}{4} \mathrm{lb}$. \\
Corn meal & $1 \mathrm{lb} .3 \mathrm{oz}$. \\
Oatmeal & $1 \mathrm{lb} .3 \mathrm{oz}$. \\
Hominy & $2 \mathrm{lb}$. \\
\multicolumn{2}{c}{ Amount carried forward } \\
51
\end{tabular}

Cost $\$ .63$ 
Food

Amodnt

Amount brought forward

Rice

$2 \mathrm{lb}$.

Lentils

$2 \mathrm{lb}$.

Split peas

$1 \mathrm{lb}$.

Beans

$1 \mathrm{lb}$.

Macaroni

Bread

$1 \mathrm{lb}$.

$13 \mathrm{lb}$.

Evaporated milk

4 cans

Stew meat

$2 \mathrm{lb}$.

Chuck steak

$1 \mathrm{lb}$.

Codfish

$1 \mathrm{lb}$.

Salt pork

Lard

Bacon

Oleomargarine

Sugar

Molasses

Apples

Lemon

Bananas

Dates

Prunes

Onions

Carrots

Potatoes

Soup greens

Tomatoes

Flour

Graham flour

Soda

$\frac{1}{4} \mathrm{lb}$.

$\frac{1}{2} \mathrm{lb}$.

$\frac{1}{2} \mathrm{lb}$.

$1 \mathrm{lb}$.

$3 \frac{1}{2} \mathrm{lb}$.

2 cups

$2 \mathrm{lb}$.

1

$3 \mathrm{lb}$.

$\frac{1}{2} \mathrm{lb}$.

$2 \mathrm{lb}$.

$2 \mathrm{lb}$.

$3 \mathrm{lb}$.

$2 \mathrm{lb}$.

Cost

$\$ 1.10$

.10

.14

.06

.05

.06

.49

.40

.16

.14

.12

.05

.08

.12

.24

.18

.06

.05

.02

.12

.07

.20

.05

.05

.06

.02

1 can

.06

7 cups

1 cup

.05

.01

.005 
Food

Amount

Cost

Amount brought forward

Loose cocoa

4 oz.

Cocoa shells

$1 \mathrm{lb}$.

Tea

Coffee

$\frac{1}{4} \mathrm{lb}$.

$\$ 4.31$

Junket

$\frac{1}{2} \mathrm{lb}$.

.06

Spices

.04

.10

.13

.01

.01

Total . . . . $\$ 4.66$

\section{Estimate of Cost First Day}

Breakfast

Oatmeal, milk and sugar

Bread and butter

Coffee - c o c o a shells for children

Dinner

Meat balls and rice with brown gravy

Boiled onions

Bread and butter

Sliced bananas with lemon juice
Food

Oatmeal

Milk

Sugar

Bread

Butter (oleo)

Coffee

Cocoa shells
AModNT

2 cups

$1 \mathrm{qt}$.

$\frac{1}{2} \mathrm{lb}$.

$1 \frac{1}{2} \mathrm{lb}$.

$4 \mathrm{oz}$.

$\frac{1}{2} \mathrm{Oz}$.

1 cup
Cost

$\$ .015$

.09

.03

.05

.06

.001

.001

.12

.03

.02

.06

.02

Supper

Baking powder Flour

3 cups

.06 biscuits

Sugar syrup

Tea with lemon

Tea

$$
\text { Total } \stackrel{10 z .}{ } \cdot .+. \quad \frac{.025}{\$ .58}
$$




\begin{tabular}{|c|c|c|c|c|}
\hline & SECOND D & & & \\
\hline Breakfast & FooD & Amovnt & & Cost \\
\hline Toast & Corn meal & $1 \mathrm{lb}$. & & $\$ .03$ \\
\hline Cornmeal and & Milk & $1 \mathrm{pt}$. & & .04 \\
\hline sugar & Sugar & $\frac{1}{2} \mathrm{lb}$. & & .03 \\
\hline Coffee & Coffee & $\frac{1}{2}$ oz. & & .001 \\
\hline Cocoa shells & Cocoa shells & 1 cup & & .001 \\
\hline Dinner & Oleo & $4 \mathrm{oz}$. & & .06 \\
\hline Baked pork and & Pork & $\frac{1}{2} 1 b$. & & .05 \\
\hline beans & Beans & $1 \mathrm{lb}$. & & .06 \\
\hline Brown bread and & Apples & $1 \mathrm{lb}$. & & .03 \\
\hline butter & Bread & $2 \mathrm{lb}$. & & .08 \\
\hline Apple pudding & & & & \\
\hline Supper & & & & \\
\hline Boiled rice, sugar & Rice & $\frac{1}{2} \mathrm{lb}$. & & .03 \\
\hline and cinnamon & Cocoa & 2 oz. & & .04 \\
\hline Cocoa - milk & Milk & $1 \mathrm{pt}$. & & .04 \\
\hline & Total & $\cdot \cdot \cdot \cdot$ & . $\cdot$ & 8.47 \\
\hline & ThIRD DA & & & \\
\hline Breakfast & Food & AMount & & Cost \\
\hline Hom in y, milk, & Hominy & 2 cups & & $\$ .04$ \\
\hline sugar & Sugar & $\frac{1}{2} \mathrm{lb}$ & & .03 \\
\hline Coffee - toast & Coffee & $\frac{1}{2} o z$. & & .001 \\
\hline Cocoa shells for & Cocoa shells & 1 cup & & .001 \\
\hline children & Milk & $1 \mathrm{pt}$. & & .04 \\
\hline Dinner & & & & \\
\hline Baked rice and & Rice & 1 cup & & .03 \\
\hline cheese & Cheese & $\frac{1}{4} \mathrm{lb}$. & & .05 \\
\hline Fried hominy & Bread & $2 \mathrm{lb}$. & & .06 \\
\hline Bread and butter & Oleo & 4 oz. & & .06 \\
\hline Junket & Junket & & & .01 \\
\hline Amount carried & orward & & & $\$ .32$ \\
\hline
\end{tabular}


Supper

Food

Amount

Cost

Amount brought forward

$\$ .32$

Creamed codfish Codfish

$1 \mathrm{lb}$.

.12

on toast

Prunes

$1 \mathrm{lb}$.

.08

Stewed prunes

Tea

$1 \mathrm{oz}$.

.025

Bread and butter

Tea

Total . . . . $\overline{\$ .54}$

\section{Fourth Day}

Breakfast

Oatmeal wafers

Cocoa shells

Dinner

Escalloped eggs

Baked potatoes

Bread and butter
FooD

Oatmeal

Cocoa shells

Oleo
AMount

2 cups

1 cup

$4 \mathrm{oz}$.
Cost

$\$ .04$

.001

.06

Eggs

Potatoes

6

.18

Bread

1 qt.

$1 \frac{1}{2} \mathrm{lb}$.

Supper

Macaroni and

Macaroni

$1 \mathrm{lb}$.

.07 cheese

Apple sauce

Cheese

$\frac{1}{4} \mathrm{lb}$.

.05

Apples

$1 \mathrm{lb}$.

.03

Tea - bread

Tea

$1 \mathrm{oz}$.

\section{Fifth DAY}

Breakfast

Stewed prunes

Coffee-cocoa shells

Graham drop cakes
Food

Prunes

Coffee

Cocoa shells

Drop cakes

Bread
AMOUNT

$1 \mathrm{lb}$.

$1 \mathrm{oz}$.

1 cup
Cost

$\$ .08$

.01

.001

.06

$\$ .25$

Amount carried forward 
Dinner

Food

Amount

CosT

Amount brought forward

$\$ .25$

Split peas and Peas

$1 \mathrm{lb}$.

.06

bacon

Bacon

$\frac{1}{2} \mathrm{lb}$.

.12

Stewed tomatoes Tomatoes

1 can

.08

Bread and butter

Supper

Rice and lentils

Rice

$1 \mathrm{lb}$.

.08

Cocoa

Gingerbread

Lentils

Gingerbread

.04

Total

$\frac{1}{2} \mathrm{lb}$.

$\frac{.18}{\$ .81}$

\section{Sixth Day}

Breakfast

Food

Amount

CosT

Corn meal mush,

Corn meal

1 cup

$\$ .01$ milk and sugar

Milk

1 qt.

.09

Toast - coffee

Coffee

$1 \mathrm{oz}$.

Cocoa shells for Cocoa shells 1 cup children

Dinner

Stew with vegeta- Stew bles and gravy Bread

Bread and butter Oleo

$1 \frac{1}{2} \mathrm{lb}$.

Date marmalade

Dates

4 oz.

$1 \mathrm{lb}$.

.06

.08

.08

Supper

Lentil soup, crou- Lentils

$1 \mathrm{lb}$.

.06 tons

Cocoa

2 oz.

.02

Bread and butter

Cocoa 


\section{Seventh Day}

Breakfast

Food

AMOUNT

Cost

Corn meal mush

Corn meal

2 cups

$\$ .02$

fried

Cocoa shells

Cocca shells

.001

Bread

Oleo

$1 \frac{1}{2} \mathrm{lb}$.

.06

4 oz.

Dinner

Beef soup with Soup

vegetables - Pudding

croutons

Baked Indian pudding

Supper

Fish balls

Fish

Bread and butter

Tea - milk

Potatoes

Milk

Tea

Second Set of Bills of Fare Supplies for Week

FooD

Milk

Loose oatmeal

Corn meal

Potatoes

Onions

Cabbage

Split peas

Lentils
AModxT

$7 \mathrm{qt}$.

$1 \mathrm{lb} .3$ oz.

$2 \mathrm{lb}$.

3 qt.

$2 \mathrm{lb}$.

$4 \mathrm{lb}$.

1 cup

$1 \mathrm{lb}$.
Cost

$\$ .63$

.05

.05

.24

.05

.05

.03

.07

Amount carried forward 
FooD

AMounT

Cost

Amount brought forward

Cheese

Rice

Dates

Bread

Butter

Loose Macaroni

Evaporated Milk

Prunes

Salt cod

Loose cocoa

Coffee

Cocoa shells

Eggs

Liver

Bacon

Can tomatoes

Currants

Heart

Lard

Sugar

Brown sugar

Haddock

Bananas

Oranges

Herbs for stuffing

heart and fish

Skirt steak

Tea

Molasses $\frac{3}{4} \mathrm{lb}$.

4 tbsp.

$\frac{1}{2} \mathrm{lb}$.

$12 \mathrm{lb}$.

$1 \mathrm{lb}$.

$1 \mathrm{lb}$.

3 cans

$1 \mathrm{lb}$.

$1 \mathrm{lb}$.

$4 \mathrm{oz}$.

$\frac{1}{2} \mathrm{lb}$.

$1 \mathrm{lb}$.

13

$1 \mathrm{lb}$.

$\frac{1}{2} \mathrm{lb}$.

1 can

1 cup

$4 \mathrm{lb}$.

6 oz.

$3 \frac{1}{2} \mathrm{lb}$.

$\frac{1}{2} \mathrm{lb}$.

$4 \mathrm{lb}$.

12

3

$1 \frac{1}{2} \mathrm{lb}$.

$\frac{1}{4} \mathrm{lb}$.

$2 \frac{1}{2}$ cups
$\$ 1.17$

.15

.01

.08

.35

.35

.10

.30

.12

.12

.06

.13

.04

.35

.15

.12

.06

.05

.24

.06

.18

.04

.38

.20

.10

.02

.21

.10

.075

$\$ 5.335$ 
FOoD

Amount

Cost

Amount brought forward

Flour

Ginger

Soda

Samp

Hominy

Baking powder

Pie meat

Greens

Junket

Crackers

Apples

Small fish

Lima beans

Apricots

Herring

Turnip

Salt pork

Carrots
7 cups

4 tsp.

4 tsp.

2 cups

2 cups

8 tsp.

$1 \frac{1}{2} \mathrm{lb}$.

$1 \mathrm{qt}$.

1

$\frac{1}{2} \mathrm{lb}$.

$2 \mathrm{lb}$.

$3 \mathrm{lb}$.

1 cup

$\frac{3}{4} \mathrm{lb}$.

$1 \mathrm{lb}$.

$2 \mathrm{lb}$.

$\frac{1}{4} \mathrm{lb}$.

2 lbs.
$\$ 5.335$

.05

.006

.005

.02

.02

.02

.20

.12

.01

.06

.05

.27

.028

.14

.09

.03

.05

.05

Total . . . $\$ \frac{\$ 6.55}{05}$

\section{First Day}

Breakfast

Oatmeal mush

Bread and butter

Coffee - c o c o a shells for children
Food

Dry oatmeal

Bread

Milk

Sugar

Coffee

Cocoa shells

Cocoa
Amoun T

Cost

$\$ .015$

.03

.09

.03

.015

.006

$\$ .186$ 
Dinner

Foon

Amover

Cosr

Amount brought forward

Split pea soup

Peas

1 cup

Croutons

Salt pork

$1 \mathrm{lb}$.

.03

Scalloped cabbage Onion

Bread and butter

Bread

8 slices

.02

Cream of rice

Cabbage

$4 \mathrm{lb}$.

.05

Flour

$4 \mathrm{lb}$.

Evapor. milk

61 cups

.098

Rice

4 tsp.

.01

Supper

Nutmeg

Codfish hash

Codfish

$\frac{1}{2} \mathrm{lb}$.

Potatoes

$1 \mathrm{lb}$.

Cocoa

Prunes

Butter

$2 \frac{2}{7} \mathrm{oz}$.

.05

Cocoa

2 oz.

.03

Sugar

$\frac{1}{2} \mathrm{lb}$.

Prunes

$1 \mathrm{lb}$.

Second Day

Breakfast FooD

Axodxr

CosT

Cornmeal mush, Sugar

$1 \mathrm{lb}$.

$\$ .015$

milk, sugar

Corn meal

2 cups

Scrambled eggs

Eggs

5

.135

Coffee - c o c O a

Coffee

$1 \mathrm{oz}$.

.015

shells for chil-

Cocoa shells

1 cup

dren

Milk

1 qt.

Dinner

Stuffed heart

Heart

$4 \mathrm{lb}$.

Browned potatoes Potatoes

$2 \mathrm{lb}$.

.24

Herbs

.048

Mashed onions

Onions

$1 \mathrm{lb}$.

Bread and butter

Bread

1 (.06 loaf)

Butter

$22 \mathrm{oz}$.

Amount carried forward 
$\begin{array}{llll}\text { Supper } & \text { Food } & \text { Ayount } & \text { Cost }\end{array}$

Amount brought forward

$\$ .699$

Fried mush

Cold mush

2 cups

.015

Brown sugar syrup

Baked bananas

Brown sugar

$\frac{1}{2} \mathrm{lb}$.

Bananas

5

.04

Bread and butter

Tea

$1 \mathrm{oz}$.

.08

.025

Tea

Total . . . . $\overline{\$ .859}$

\section{ThIRD DAX}

$\begin{array}{llll}\text { Breakfast } & \text { Food } & \text { Axoorr } & \text { Cost } \\ \text { Minced liver } & \text { Milk } & 1 \mathrm{qt} . & \$ .09 \\ \text { Bacon for children } & \text { Coffee } & 1 \mathrm{oz} . & .015 \\ \text { Toast } & \text { Evapor. milk } & 2 \text { cups } & .03 \\ \text { Coffee - cocoa } & \text { Liver } & 1 \mathrm{lb} \text {. } & .15 \\ \text { shells for chil- } & \text { Bacon } & \frac{1}{2} \text { lb. } & .12 \\ \text { dren } & \text { Bread } & 1 \text { stale .08 loaf } & .05 \\ & \text { Cocoa shells } & 1 \text { cup } & .006\end{array}$

Dinner

Baked lentils with

Lentils

$1 \mathrm{lb}$.

.07

tomato sauce

Tomatoes

1 can

.06

Stewed potatoes

Potatoes

1 s. $l \mathrm{~b}$.

.042

Bread pudding

Currants

Eggs

$\frac{1}{2}$ cup

2

.025

Sugar

$\frac{1}{2} \mathrm{lb}$.

.054

.015

Supper

Cold sliced heart

Heart (second day)

Bread and butter

Butter

$2 \frac{2}{7} \mathrm{oz}$.

.05

Steamed date mar- Dates

$\frac{1}{2} \mathrm{lb}$.

.08

malade

Oatmeal wafers

Oatmeal

2 cups

.015

Flour

2 cups

.014

Total . . . . $\overline{\$ 886}$ 
Fourth Day

\begin{tabular}{|c|c|c|c|}
\hline Breakfast & FOOD & AMOUNT & Cost \\
\hline \multirow{2}{*}{$\begin{array}{l}\text { Oatmeal molded } \\
\text { with bananas }\end{array}$} & Sugar & $\frac{1}{2} \mathrm{lb}$. & $\$ .03$ \\
\hline & Milk & 1 qt. & .09 \\
\hline Codfish on toast & Bananas & 4 & .05 \\
\hline \multirow{6}{*}{$\begin{array}{l}\text { Coffee-cocoa } \\
\text { shells for chil- } \\
\text { dren }\end{array}$} & Evapor. milk & 4 cups & .06 \\
\hline & Coffee & $1 \mathrm{oz}$. & .015 \\
\hline & Cocoa shells & 1 cup & .006 \\
\hline & Codfish & $\frac{1}{2} \mathrm{lb}$ & .06 \\
\hline & Flour & 2 tsp. & \\
\hline & Oatmeal & & .015 \\
\hline \multicolumn{4}{|l|}{ Dinner } \\
\hline Baked haddock & Haddock & $4 \mathrm{lb}$. & .28 \\
\hline Mashed carrots & Carrots & $2 \mathrm{lb}$. & .05 \\
\hline Baked potatoes & Potatoes & $1 \frac{1}{2} \mathrm{lb}$. & .036 \\
\hline Indian pudding & Molasses & $\frac{1}{2}$ cup & .015 \\
\hline \multirow[t]{2}{*}{ Bread and butter } & Bread & 1 stale .08 loaf & .05 \\
\hline & Butter & $2 \mathrm{Oz}_{\mathrm{f}}$ & .05 \\
\hline \multicolumn{4}{|l|}{ Supper } \\
\hline Bread and butter & Ginger & 1 tsp. & .0015 \\
\hline Cocoa & Flour & 2 cups & .014 \\
\hline Gingerbread & Cocoa & $2 \mathrm{oz}$ & .03 \\
\hline \multirow[t]{4}{*}{ Cheese } & Cheese & $\frac{1}{1} \mathrm{lb}$. & .05 \\
\hline & Soda & 2 tsp. & .0025 \\
\hline & Molasses & 1 cup & .03 \\
\hline & Lard & $2 \mathrm{oz}$. & .02 \\
\hline
\end{tabular}

\section{Fifth Day}

\begin{tabular}{lccc} 
Breakfast & Food & Asrousr & Cost \\
Samp - milk - & Milk & $1 \mathrm{qt}$. & $\$ .09$ \\
sugar & Eggs & 1 & .027 \\
Kippered herring & Samp & 2 cups & .02 \\
\multicolumn{2}{c}{ Amount carried forward } & & $\$ .137$
\end{tabular}


Food

Amount brought forward

Corn meal muffins Herring

Coffee-cocoa Corn meal

shells for chil- Baking powder

dren
Flour

Sugar

Coffee

Cocoa shells

Amount

Cost

$\$ .137$

$1 \mathrm{lb}$.

1 cup

.09

.008

.01

.007

.045

.015

.006

Dinner

Meat pie - potato

Stew meat

$1 \frac{1}{2} \mathrm{lb}$.

.20

crust

Potatoes

$1 \mathrm{lb}$.

.024

Spinach

Onions

$1 \mathrm{lb}$.

.025

Bread and butter

Junket tablet

.01

Caramel junket

Spinach

$1 \mathrm{qt}$.

.12

Supper

Cream of fish Evapor. milk 4 cups .06 chowder

Parsley

.01

Cheese - crackers

Bread and butter

Cheese

Crackers

Apple sauce

Bread

Butter

Apples

Fish

$\frac{1}{4} 1 \mathrm{~b}$.

$\frac{1}{2} \mathrm{lb}$.

.05

.06

1 (.08 loaf)

.05

$2 \frac{2}{7} \mathrm{oz}$.

.05

$2 \mathrm{lb}$.

.05

$1 \mathrm{lb}$.

.12

Total

$\$ 1.147$

\section{Sixth DAy}

Breakfast

Pan fish

Browned potatoes

Buttered toast
Food

Fish

Potatoes

Bread
AMount

$2 \mathrm{lb}$.

$1 \mathrm{lb}$.

1 (.08 loaf)
Cost

$\$ .15$

.024

Amount carried forward 


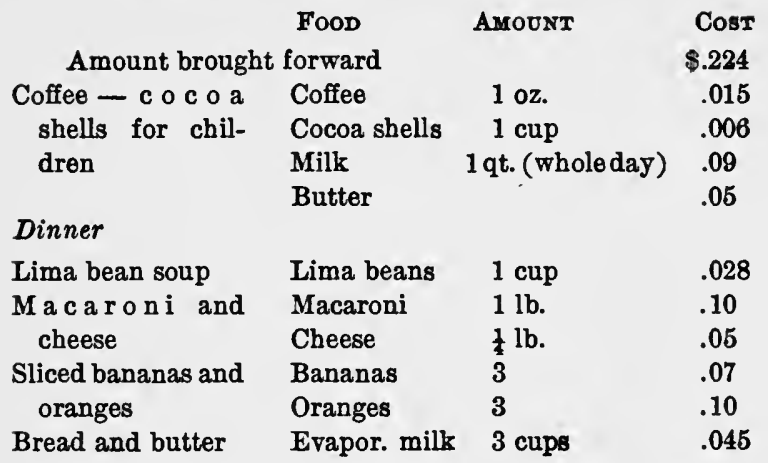

Supper

Toasted bread

Molasses

1 cup

.03 crumbs and milk

Soda

2 tsp. .0025

Stewed apricots

Flour

$2 \frac{1}{2}$ cups

.021

Ginger cookies

Ginger

1 tsp.

.0045

Apricots

Lard

s lb.

.14

4 oz.

.04

Total

$\$ 1.016$

\section{Seventh Day}

\begin{tabular}{|c|c|c|c|}
\hline Breakfast & FooD & AMOUNT & Cost \\
\hline \multirow{2}{*}{$\begin{array}{l}\text { Hominy, milk, } \\
\text { sugar }\end{array}$} & Hominy & 2 cups & $\$ .02$ \\
\hline & Milk & 1 qt. & .09 \\
\hline Soft-cooked eggs & Sugar & $1 \mathrm{lb}$. & .06 \\
\hline Bread and butter & Eggs & 5 & .135 \\
\hline \multirow{4}{*}{$\begin{array}{l}\text { Coffee - c o c o a } \\
\text { shells for chil- } \\
\text { dren }\end{array}$} & Bread & 1 (.08 loaf) & .05 \\
\hline & Butter & $2 \frac{2}{y} \mathrm{oz}$ & .05 \\
\hline & Coffee & $2 \mathrm{oz}$ & .03 \\
\hline & Cocoa shells & 1 cup & .006 \\
\hline \multicolumn{3}{|c|}{ Amount carried forward } & $\$ .441$ \\
\hline
\end{tabular}


Dinner

Food

Amouxt

$\operatorname{Cos} T$

Amount brought forward

Braised skirt steak

Steak

Baked potatoes

Potatoes

Hashed turnips

Turnips

Bread pudding

Currants

$\$ .441$

$1 \frac{1}{2} \mathrm{lb}$.

.21

$1 \frac{3}{4} \mathrm{lb}$.

.042

2 lbs.

.03

1 cup

.025

Supper

Corn meal pan cake Sugar syrup

Corn meal $\frac{1}{2}$ cup

Tea - bread and Tea

$1 \mathrm{oz}$.

butter

Total . . . $\overline{\$ .782}$

\section{Thrrd SeT of Bills of Fare}

\section{Supplies for Week}

Food

Oatmeal

Milk

Sugar

Bread

Butter@35\& lb.

Eggs (15)@3申

Coffee

Onions

Potatoes

Junket tablet

Catsup

Flour

Baking powder

Apples
Axount

$1 \frac{1}{6} \mathrm{lb}$.

14 qt.

8 cups, $3 \frac{1}{2}$ lbs.

$17 \mathrm{lb}$.

$1 \frac{3}{4} \mathrm{lb}$.

$1 \frac{2}{3} \mathrm{lb}$.

42 tablespoons

1 qt., $3 \frac{1}{2}$ lb.

$3 \frac{1}{2}$ qt., $12 \frac{1}{4} \mathrm{lb}$.

1

1 bottle

$3 \mathrm{lb}$.

$6 \mathrm{lb}$.
Cost

$\$ .03$

1.26

.18

.51

.62

.45

.25

.10

.28

.01

.10

.12

.01

.12

$\$ 4.04$

Amount carried forward 
Food

Amount

Amount brought forward

Cocoa

Wheatena

Codfish

Haddock

Spinach

Corn meal

Lentils

Apricots

Tea

Cream of Wheat

Dates

Liver

Bacon

Pot roast

Cookies

Carrots

Bananas

Gingerbread

Sweet potatoes

Cornstarch

Cabbage

Cake

Beans

Pork

Pickles

Tomatoes

Rice

Gelatine

Lemons $\frac{1}{3} \mathrm{lb}$.

$\frac{1}{2} \mathrm{lb}$.

$1 \mathrm{lb}$.

$3 \mathrm{lb}$.

1 qt., $1 \frac{1}{2}$ lb.

$1 \frac{1}{2} \mathrm{lb}$.

$1 \mathrm{lb}$.

$\frac{3}{4} \mathrm{lb}$.

$\frac{1}{5} \mathrm{lb}$.

$\frac{1}{2} \mathrm{lb}$.

$\frac{1}{2} \mathrm{lb}$.

$\frac{3}{4} \mathrm{lb}$.

$\frac{1}{2} \mathrm{lb}$.

5 lbs.

$1 \mathrm{lb}$.

$4 \mathrm{lb}$.

$1 \mathrm{lb}$.

$1 \mathrm{lb}$.

$2 \mathrm{lb}$.

$\frac{1}{2} \mathrm{lb}$.

$4 \mathrm{lb}$.

$1 \mathrm{lb}$.

$\frac{1}{2} \mathrm{lb}$.

$\frac{1}{2} \mathrm{lb}$.

$1 \frac{1}{2} \mathrm{lb}$.

$1 \mathrm{lb}$.

1 oz.

$1 \mathrm{lb}$. (4)
Cost

$\$ 4.04$

.08

.02

.12

.21

.18

.06

.07

.14

.10

.02

.06

.10

.12

.70

.12

.10

.18

.15

.10

.01

.13

.13

.06

.10

.05

.12

.08

.02

.10

$\$ 7.47$

Amount carried forward 
FOoD

AMrounT

$\operatorname{Cos} r$

Amount brought forward

Salmon (large can)

$1 \frac{1}{2} \mathrm{lb}$.

.15

Stew meat

$3 \mathrm{lb}$.

.28

Vanilla

.01

Corned beef

$3 \mathrm{lb}$.

Ox tail

$1 \mathrm{lb}$.

.12

Oil

.08

Beef roll

Sweet potatoes

$1 \frac{1}{2} \mathrm{lb}$.

.22

$1 \mathrm{lb}$.

.05

Flank steak

$1 \frac{1}{2} \mathrm{lb}$.

.21

Cheese

$\frac{1}{2} \mathrm{lb}$.

\section{First Day}

$\begin{array}{llll}\text { Breakfast } & \text { Food } & \text { Axousr } & \text { Cosr } \\ \text { Oatmeal - milk }- & \text { Oatmeal } & 2 \text { cups } & \$ .015 \\ \text { sugar } & \text { Milk } & 1 \text { qt. } & .09 \\ \text { Bread and butter } & \text { Sugar } & 1 \mathrm{lb} . & .03 \\ \text { Scrambled eggs } & \text { Bread } & 2 \mathrm{lb} . & .06 \\ \text { Coffee } & \text { Butter } & 4 \mathrm{oz} . & .09 \\ & \text { Eggs } & 6 & .18 \\ & \text { Coffee } & 1 \mathrm{oz} . & .015\end{array}$

Dinner

Flank steak - Flank steak $1 \frac{1}{2} \mathrm{lb}$. stuffed

Onions

$2 \mathrm{lb}$.

.06

Escalloped onions

Potatoes

$2 \mathrm{lb}$.

.04

Browned potatoes

Junket tablet

.01

Junket

Milk

1

.09

Coffee

1 qt.

Amount carried forward 
Supper

Food

Amount

Cost

Amount brought forward

Cold sliced meat

Flour

2 cups

$\$ .89$

Catsup

Apples

$3 \mathrm{lb}$.

Baking powder Milk

1 pt.

biscuits

Cocoa

2 oz.

Baked apples

Cocoa

$$
\text { Total . . . . . } \$ 1.11
$$

\section{Second Day}

Breakfast

Food

AMOUNT

Cost

Wheatena - milk

Wheatena

$\frac{1}{2} \mathrm{lb}$.

- sugar

Milk

1 qt.

$\$ .02$

Toast, buttered

Sugar

$1 \mathrm{lb}$.

Creamed codfish Bread

$2 \frac{1}{2} \mathrm{lb}$.

on toast

Butter

$4 \mathrm{oz}$.

.12

Codfish

$1 \mathrm{lb}$.

Coffee

Coffee

$1 \mathrm{oz}$.

Dinner

Baked haddock, Haddock

$3 \mathrm{lb}$.

.21 egg sauce

Eggs

Creamed potatoes

Potatoes

2

.08

Spinach

$2 \mathrm{lb}$.

.04

$1 \frac{1}{2} \mathrm{lb} . \quad .16$

Bread and butter

Apples

$2 \mathrm{lb}$.

Apple pudding

Supper or Luncheon

Corn bread

Corn bread

Lentil soup

Lentils

$1 \mathrm{lb}$.

Stewed apricots

Milk

1 qt.

Tea

Apricots

$\$ \mathrm{lb}$.

Tea

$1 \mathrm{oz}$. 


\section{Third Day}

Breakfast

FOOD

Amount

Cost

Cream of wheat Milk

$1 \mathrm{qt}$.

with dates

Cream of wheat

$\frac{1}{2} \mathrm{lb}$.

Bread and butter Dates

Liver and bacon

Coffee

Bread

$\frac{1}{2} \mathrm{lb}$.

$2 \mathrm{lb}$.

$\$ .02$

Butter

$4 \mathrm{oz}$.

Liver

$\frac{3}{4} \mathrm{lb}$.

Bacon

$\frac{1}{2} \mathrm{lb}$.

Coffee

1 oz.

Dinner

Pot roast of beef

Pot roast

$5 \mathrm{lb}$.

with carrots and

Carrots

$1 \mathrm{lb}$. onions

Onions

$\frac{1}{2} \mathrm{lb}$.

.01

Bread and butter

Bananas

$1 \mathrm{lb}$.

Sliced bananas coffee

Supper

Milk toast

Cheese, bread and butter

Gingerbread

Tea
Milk

Cheese

Gingerbread

Tea
$1 \mathrm{qt}$.

$\frac{1}{2} \mathrm{lb}$.

8.09

.10

.15

.02

$$
\text { Total . . . . } \$ \overline{\$ 1.75}
$$

\section{Fourth Day}

Breakfast

Pancakes

Bread and butter

Beef hash

Coffee
FooD

Flour

Bread

Milk

Coffee
Amount

$1 \mathrm{lb}$.

$2 \mathrm{lb}$.

1 qt.

$1 \mathrm{oz}$.
CosT

$\$ .04$

.06

.09

.015

$\$ .205$

Amount carried forward 
Dinner

Food

AMount

Cost

Amount brought forward

$\$ .205$

Warmed over roast Potatoes

1 qt.

Baked sweet pota-

Butter

4 oz.

Pudding

Bread and butter

Chocolate cornstarch pudding

Coffee

Supper

Cream of fish soup Onions

Bread and butter

Oil

Cabbage salad

Cabbage

Cocoa - cake

Cocoa

$20 z$.

.03

Cake

Sugar

$\frac{1}{2} \mathrm{lb}$.

.03

Total

$\$ .87$

\section{Fifth Day}

$\begin{array}{llll}\text { Breakfast } & \text { Food } & \text { Amount } & \text { CosT } \\ \text { Omelet } & \text { Bread } & 2 \mathrm{lb} . & \$ .06 \\ \text { Creamed potatoes } & \text { Eggs } & 5 & .15 \\ \text { Coffee } & \text { Potatoes } & 2 \mathrm{lb} . & .04 \\ & \text { Milk } & 2 \mathrm{qt} . & .18 \\ & \text { Sugar } & \frac{1}{2} \mathrm{lb} . & .03 \\ & \text { Butter } & 4 \mathrm{oz} . & .09 \\ \text { Dirner } & & & \\ \text { Baked beans }- & \text { Beans } & 1 \mathrm{lb} . & .06 \\ \text { pork } & \text { Pork } & \frac{1}{2} \mathrm{lb} . & .05 \\ \text { Pickles } & \text { Pickles } & & .05 \\ \text { Scalloped tomatoes } & \text { Tomatoes } & 1 \mathrm{qt} . & .12 \\ \text { Boiled rice } & \text { Rice } & \frac{1}{2} \mathrm{lb} . & .04\end{array}$

Lemon jelly

Amount carried forward 
Supper

Foon

Amount

Cost

Amount brought forward

Salmon loaf

Salmon

$1 \mathrm{can}$

Bread and butter

Egg

1

.03

Apple sauce

Apples

$1 \mathrm{lb}$.

.03

Tea

Tea

1 oz.

.025

Total . . . . $\$ \overline{\$ 10}$

\section{SiXth DAY}

Breakfast

Oatmeal

Milk - sugar

Bread and butter

Baked apples coffee
Foon

Milk

Oatmeal

Sugar

Bread

Apples

Coffee

Butter
Amount

2 qt.

2 cups

$\frac{1}{2} \mathrm{lb}$.

$2 \mathrm{lb}$.

$1 \mathrm{lb}$.

$1 \mathrm{oz}$.

4 oz.
Cost

$\$ .18$

.015

.03

.06

.03

.015

.09

Dinner

Meat pie

Meat

Carrots

$3 \mathrm{lb}$.

.28

Creamed carrots

Bread and butter

Potatoes

$2 \mathrm{lb}$.

.06

$1 \mathrm{lb}$.

.02

Homemade ice Ice cream cream

Coffee

Supper

Cheese fondu fried potatoes Cheese
Eggs
Tea

$1 \mathrm{lb}$.

Bread and butter Tea

$1 \mathrm{oz}$. 


\section{Seventh Day}

\begin{tabular}{|c|c|c|c|}
\hline Breakfast & Food & AMOUNT & Cost \\
\hline Oatmeal & Coffee & $1 \mathrm{oz}$. & $\$ .015$ \\
\hline French toast & Milk & 2 qt. & .18 \\
\hline Coffee & Oatmeal & 2 cups & .015 \\
\hline Bread and butter & $\begin{array}{l}\text { Sugar } \\
\text { Bread }\end{array}$ & $\begin{array}{l}\frac{1}{2} \mathrm{lb} \text {. } \\
3 \mathrm{lb} \text {. }\end{array}$ & $\begin{array}{l}.03 \\
.09\end{array}$ \\
\hline \multicolumn{4}{|l|}{ Dinner } \\
\hline $\begin{array}{l}\text { Corned beef } \\
\text { Scalloped cabbage }\end{array}$ & $\begin{array}{l}\text { Beef } \\
\text { Cabbage }\end{array}$ & $3 \mathrm{lb}$. & $\begin{array}{l}.42 \\
.035\end{array}$ \\
\hline $\begin{array}{l}\text { Potatoes } \\
\text { Indian pudding - } \\
\text { coffee }\end{array}$ & Potatoes & $2 \mathrm{lb}$. & .05 \\
\hline \multicolumn{4}{|l|}{ Supper } \\
\hline $\begin{array}{l}\text { Oxtail soup } \\
\text { Potato salad }\end{array}$ & $\begin{array}{l}\text { Oxtail } \\
\text { Cookies }\end{array}$ & $1 \mathrm{lb}$. & $\begin{array}{l}.12 \\
.10\end{array}$ \\
\hline Bread and butter & Tea & $1 \mathrm{oz}$. & .025 \\
\hline Cookies - tea & Total & & $\frac{.09}{\$ 1.215}$ \\
\hline
\end{tabular}

\section{DIET FOR CHILDREN}

Food for Young Children

(MISS FARMER)

From Twelve to Sixteen Months

If perfectly well, the child may be fed at these hours :-

$\begin{array}{llrl}\text { Breakfast. . . } & 7.30 & \text { Dinner . . } & 2.30 \\ \text { Luncheon. . . } & 11.30 & \text { Supper . . } & 5.30\end{array}$ 


\section{Breakfast. -}

Cereal, well cooked and strained, with a very little sugar. Glass of milk.

\section{Luncheon. -}

Strained cereal one part, with top milk, three parts.

\section{Dinner. -}

Soft cooked egg, or beef or chicken or mutton broth. Slice of stale bread and butter. Steamed rice, junket, or custard.

Supper.-

Same as luncheon.

Sirteen to Twenty-four Months

Additions to breakfast. -

Soft cooked egg.

To luncheon. -

Bread and butter.

To dinner. -

Baked potato, rice, beef juice.

If for any reason the child is not well, do not give this diet without advice of physician. 
Food for School Children

The good health of a grown person depends largely on the food he ate when he was a child. Children must eat at regular times, and should be given food that will make muscle and bone and flesh.

The breakfast of a school child should be: A plate of well-cooked cereal, milk and sugar, a soft-cooked egg, bread and butter, milk or cocoa or cocoa shells.

The dinner should be: Some meat cooked without grease, a baked potato, a fresh vegetable, a simple pudding, bread and butter.

The supper should be: Bread and butter, stewed fruit, milk or cocoa.

School children who are healthy may use all the bills of fare in this book.

Foods Not Good for Children

$\begin{array}{lll}\text { Tea } & \text { Coffee } & \text { Spices } \\ \text { Beer } & \text { Pickles } & \text { Pies } \\ \text { Fried food } & \text { Pork } & \text { Veal }\end{array}$




\section{FEEDING THE SICK}

\section{General Rules}

All persons of experience agree that proper feeding is absolutely necessary for good health, and that many diseases are caused directly by badly chosen or improperly prepared food. On the other hand, when illness is present, sensible feeding will do much to relieve it.

The time to begin to take care that a person is well fed is when he is a child. Sometimes a mother says, "I can give my baby or my child tea, or fried meat, or pie, because it does not make him sick." It is true that such food may not make the child ill at once, but sooner or later the bad effects will be seen, either in a disturbed stomach or in general weakness from under nourishment.

The first thing to do in feeding a sick person is to find out from a physician what the trouble is, and then to take his advice as to what food shall be given.

As a usual thing sick people should eat less than well persons, so as to rest the 
stomach and bowels, but the quantity varies greatly.

Great care should be taken in the preparation of food for the sick. Follow all directions very carefully. Serve hot food very hot. Serve cold food very cold. Have everything very clean. Use dishes as attractive as possible. Arrange the tray so that it will be as dainty as possible. Remove soiled dishes at once. Cleanse dishes by covering with cold water, then stand pan on stove, bring water slowly to boiling point, and let boil ten minutes. Never taste food that is to be given to a sick person with the spoon which he is to use, nor allow him to use the spoon of any one else.

\section{SPEcial Diets 1}

1. Fluid in cases of high fever or any condition where solid food cannot be taken.

One glass or cup of any of the following every two hours, at least 8 cups during the day.

Milk

Buttermilk

Kumyss Milk with barley

${ }^{1}$ Dr. Mosenthal. 
Malted milk.

Any soup without solid matter in it.

Coffee, tea, or cocoa, each to be made half milk.

Lemonade with white of egg.

Orangeade with white of egg.

Junket. Custard. Ice cream.

Eggnog \} either of these may be given once a Milk punch $\}$ day, in place of milk, where ordered.

2. Soft solid diet. This includes creamed chicken, eggs, custards, milk toast, etc.

3. Convalescent diet or diet for upset digestion.

\section{Soft Solid Diet}

\section{Breakfast. ${ }^{1}$ -}

Boiled milk with cocoa or coffee.

Any cooked cereal, strained, with cream.

Dry toast, buttered.

$1 \mathrm{egg}$, soft-boiled or poached.

10 A.M. -

Glass of milk, or malted milk, or milk with beaten egg.

\section{Lunch. -}

Thick potato, pea or bean soup with toast soaked in it, or boiled rice with milk or cream.

2 soft-boiled, scrambled, or poached eggs.

1 Dr. Mosenthal. 
4 P.M. -

Bouillon with rice, or chicken broth and toast or dry crackers.

\section{Supper. -}

Minced chicken or rare scraped beef.

Mashed or well-baked potatoes.

Buttered toast.

Junket, or custard, or wine or coffee jelly, or tapioca pudding.

10 P.M. -

As at 10 A.M.

\section{General Directions}

Chew your food extremely carefully.

Eat and drink very slowly.

In preparing food, use no spices and as little salt as possible.

Eat and drink nothing beside articles given on the list, except water.

\section{Diet For Constipation 1}

Breakfast. -

Any fruit (fresh, cooked, preserved, or dried).

Shredded wheat, Thomas uncooked wheat biscuit,

${ }^{1}$ Dr. Mosenthal. 
or oatmeal, or grape nuts, or toasted corn flakes, with cream if possible, otherwise a small amount of milk, and sugar or molasses.

Bread (see list below).

Butter, jam, jelly, honey.

Coffee with cream and sugar.

\section{Lunch and Dinner. -}

Soup, any kind, except those thickened with flour, or containing milk.

Fish, meat, or eggs in moderation; eat as much of the fat as possible.

Vegetables: fresh or canned in any quantity, green salads with olive oil.

Desserts: fresh fruit, or fruit cooked or preserved is best. Jellies prepared with coffee, wine, lemon, etc. Pies, do not eat undercrust. Water ices, any amount. Ice cream, small amounts only.

Bread (see list below), and butter.

\section{General Directions. -}

Take at least a glass of water before breakfast, one in the middle of the day, and one at night; in addition as much water as may be desired.

Water, plain or vichy (or any carbonated water), buttermilk, sour milk, cider, beer, white wine are allowed.

Bread : use only graham, rye, bran, whole wheat, or corn bread.

Butter in any quantity is permitted. 
Avoid. -

Tea, red wine, milk, whiskey.

White bread, noodles, vermicelli, macaroni, all cake, rice, barley, potatoes and cheese.

\section{General Rules. -}

Have a regular time for going to the toilet. Take a daily walk in the open air.

Practice the exercises given you.

\section{Exercises. - (Each to be done 15 times).}

1. Knees stiff, bend forward and try to touch floor.

2. Bend back from hips.

3. Bend to the right and to the left from hips.

4. Rotate to the right and to the left on hips.

Diet in First Stages of Tuberculosis

The writer has had considerable experience in the planning of meals for families who have to live on a very moderate sum. The expensive food which was once thought necessary is sometimes beyond the reach of such a family, and it has been proven that much can be done by care in preparation and regularity in feeding.

A good foundation plan on which to base these diets is a modification of that used by 
the English authorities, Bardswell and Chapman, and is as follows:

\section{Breakfast. -}

Large dish of oatmeal, milk and sugar, 2 oz. of bacon or smoked fish, 2 slices of bread and oleomargarine.

\section{A.M. -}

3 slices of bread and oleomargarine with prune or date marmalade prepared at home.

\section{Luncheon. -}

$8 \mathrm{oz}$. of soup from one of the dried vegetables (vary by making part milk), 2 slices of bread and cheese, glass of milk.

\section{Dinner. -}

Plate of meat stew, slice of bread and oleomargarine, dish of well-cooked vegetables, $8 \mathrm{oz}$. of rice or tapioca pudding made with milk, glass of milk. 

THE following pages contain advertisements 1 of a few of the Macmillan publications on kindred subjects 
By WHITMAN H. JORDAN, Director of the New rork Agricultural Experiment Station

\section{Principles of Human Nutrition}

A Study in Practical Dietetics

Cloth, I2mo, 450 pages, index, \$1.75 net; by mail, \$1.89

The present work is a concise presentation of the subjectmatter related to human nutrition which will be more or less adapted to popular use, but particularly to instruction of students with moderate scientific acquirements, whether in colleges, secondary schools, short courses, schools of domestic science, or correspondence schools. The reliable knowledge bearing on the nutrition of man is mainly to be found in elaborate works on physiology and physiological chemistry, the contents of which are not generally available. Moreover, the highly technical facts are usually not centered around a philosophy of living. The aim here has been to show the adjustment of this knowledge to a rational system of nutrition without insisting upon adherence to technical details that are not feasible in the ordinary administration of the family dietary.

Throughout the author has relied upon the conclusions of those authorities and investigators whose sound scholarship in this field of knowledge is unquestioned.

BY MABEL JACQUES, with an Introduction by DR. JOHN H. PRYOR.

\section{District Nursing}

Cloth, I2mo, \$1.00 net Despite the great benefits which have resulted from district nursing, the public knows little, either of the organization or of the extent of the movement. It is to inform the great mass of readers who are interested in social advance that Miss Jacques has written District Nursing. The book is provided with a splendid Introduction by Dr. John H. Pryor.

\section{THE MACMILLAN COMPANY}

Publishers

64-66 Fifth Avenue

Now Yorl 


\section{Primary Nursing Technique}

Cloth, I2mo, \$1.25 net

This is a thoroughly honest book for nurses starting on their course of study. It is written with the one object in view of inculcating in the minds of its readers the fact that an accurate knowledge of the human body is the first essential to successful nursing. The authoress also urges thoroughness and patience as the sine qua non of the nurse. The diction of the book is admirably clear.

\section{Hygiene for Nurses}

Cloth, I2mo, $\$ 1.25$ net

"The pages of this book are full of just the information that every woman in charge of souls and bodies needs. The chapters on food, ventilation, sewage, causes and disseminatiou of disease, household, personal, and school hygiene, the hygiene of occupation, disinfection, etc., are all of the most vital general interest and should be taken to heart by every one. The task is made easy by the excellent printing of the little book, ... . which will be found an excellent book of reference." - Philadelphia Public Ledger.

\section{The Elements of Hygiene for Schools}

Cloth, I2mo, $\$ .60$ net

The author's chief aim in this book has been to present the principles of hygiene intelligently and impressively, for the sake of helping the large number of school children who, after leaving school, probably will have no further opportunities to study those principles. She has undertaken to show these young people how they may have vigor of mind and body through the observance of a few simple rules in respect to food, water, air, drainage, clothing, occupation, and exercise.

\section{THE MACMILLAN COMPANY}

Publishers

64-66 Fifth Avenue

New York 
An entirely new edition, revised and in part rewritten by

MisS CAROLYN E. GRAY

NOW READY

\section{Text-Book of Physiology and Anatomy for Nurses}

BY DIANA C. KIMBER, Revised by CAROLYN E. GRAY, Assistant Superintendent of the New rork City Training School for Nurses, Blackwell's Island.

The book has been a standard text in the best training schools for nurses ever since its publication.

It has been thoroughly revised in view of the experience of those who have used the book.

New plates and other illustrations have been added, and in every way the standing of the book as the best text on its subject for nurses' study has been reënforced.

Cloth, I2mo, fully illustrated, $\$ 2.50$ net

BY HARRY SNYDER, B.S., Professor of Agricultural Chemistry, University of Minnesota, and Chemist of the Minnesota Agricultural Experiment Station

\section{Dairy Chemistry}

Illustrated, roo pages, \$r.0o net; by mail, \$r.10 "The book is a valuable one which any dairy farmer, or, indeed, any one handling stock, may read with profit."

- Rural New Yorker.

\section{Human Foods}

Illustrated, cloth, I2mo, 362 pages, $\$ 1.25$ net A discussion of the composition and physical properties of foods, the main factors which affect their nutritive value, etc.

\section{THE MACMILLAN COMPANY}

Publishers

64-66 Fifth Avenue

New York 



UNIVERSITY OF CALIFORNIA LIBRARY Los Angeles

This book is DUE on the last date stamped below.

Form L9-32m-8,'57 (C8680s4) 444 





